
\title{
BReserch Soutere \\ Polymeric Substitution of Triazole Moieties in Cellulosic Schiff Base for Heavy Metal Complexation Studies
}

\section{R MAHALAKSHMI}

Kumaraguru College of Technology

SARAVANAN R ( $\nabla$ saravan_0021@yahoo.com)

KPR Institute of Engineering and Technology https://orcid.org/0000-0002-8988-9808

\section{P SELVAKUMAR}

Vivekanandha College of Arts and Sciences for Women

\section{S KARTHIKEYAN}

KPR Institute of Engineering and Technology

\section{RAVIKUMAR}

CBM ARTS AND SCIENCE COLLEGE

\section{Research Article}

Keywords: Modified Cellulose, Spectral studies, Adsorption isotherms, Adsorption kinetics, Desorption.

Posted Date: May 7th, 2021

DOl: https://doi.org/10.21203/rs.3.rs-413436/v1

License: (9) This work is licensed under a Creative Commons Attribution 4.0 International License. Read Full License

Version of Record: A version of this preprint was published at Journal of Polymers and the Environment on June 7th, 2021. See the published version at https://doi.org/10.1007/s10924-021-02201-7. 


\title{
Polymeric substitution of Triazole moieties in Cellulosic Schiff Base for Heavy Metal Complexation Studies
}

\author{
R. Mahalakshmi ${ }^{1}$, R.Saravanan ${ }^{2 *}$, P.Selvakumar ${ }^{3}$, M.S.Karthikeyan², L.Ravikumar ${ }^{4}$ \\ ${ }^{1}$ Department of Chemistry, Kumaraguru College of Technology, Coimbatore- 641049, India. \\ ${ }^{2 *}$ Department of Chemistry, KPR Institute of Engineering and Technology, Coimbatore - \\ 641407, India. \\ ${ }^{3}$ Department of Chemistry, Vivekanandha College of Arts \& Sciences for Women, \\ Tiruchengode-637205, Tamilnadu, India \\ ${ }^{4}$ Department of Chemistry, C.B.M. College, Coimbatore-641042, India. \\ E-mail: saravan_0021@yahoo.com Mobile Number: +91-9942567656
}

\begin{abstract}
:
The adsorption of metal ions from wastewater using Schiff base cellulose bearing pendulant heterocyclic chelating groups $(\mathrm{MC}-\mathrm{Tz})$ as a sorbent is the subject of this paper. Solid state ${ }^{13}$ C-NMR, FT-IR, SEM, and XRD spectroscopy, as well as TGA and XRD were utilized to examine the adsorbent. The batch sorption process used $\mathrm{pH}$, adsorbent dose, initial adsorbate concentration, temperature, as well as contact time to calculate the metal ion levels. The optimum $\mathrm{pH}-6.0$, with the complexation reaction and ion exchange phase as the mechanisms at work. To investigate the equilibrium concentration and temperature-dependent rate constants, various models, such as the Langmuir, Freundlich, Temkin, and Redlich-Peterson adsorption isotherm were utilized. A Kinetic study shows that the Langmuir is more in agreement with the Pseudo-second order Kinetic model. Adsorption-Desorption experiments over four cycles demonstrated the feasibility of the sorbent's regeneration potential and the measured values of enthalpy and entropy explain the essence of the adsorption process. The
\end{abstract}


objective of this research is to discover non-toxic, environmentally friendly adsorbent biodegradable components and to conduct evaluations to determine their use in wastewater treatment.

Key words: Modified Cellulose, Spectral studies, Adsorption isotherms, Adsorption kinetics, Desorption.

\section{INTRODUCTION}

Heavy metals, which are made up of a complex group of elements, remain in the atmosphere and have been shown to have significant health effects. They also play an important but less evident role in acute toxicity. It is a term used to identify the collective arrangements of metals and metalloids with an atomic density above $6 \mathrm{gcm}^{-3}$, for example Cadmium, Chromium, Copper, Mercury, Nickel, Lead, and Zinc, which are usually linked through contamination and toxic issues. Metal use in industries, vehicle exhausts, waste incineration, smelting processes, and the combustion of fossil fuels all contribute to the release of vast quantities of possibly harmful heavy metals into the environment. $\mathrm{Pb}$ roots encephalopathy, cerebral dysfunction, kidney damage, anemia, reproductive system deadliness, and behavioral abnormalities at elevated exposure levels(Obasi and Akudinobi, 2020). Cadmium is also linked to nephrotoxicity and bone damage (X. Li et al., 2020). Wilson's disease is a neurotoxic syndrome caused by copper accumulation in the lenticular nucleus of the brain and kidney failure (Gromadzka et al., 2020). Nickel compounds are carcinogenic and readily absorbed by the skin, and exposure to a concentration of $30 \mathrm{mg} / \mathrm{L}$ in the atmosphere for half an hour is lethal (Briffa et al., 2020). To control emissions, it is important to eliminate these pollutants, which necessitates the use of a cost-effective and recyclable method including adsorption. The quest for environmentally safe materials for wastewater treatment with minimal and non-hazardous by-products has become a focal point 
in recent years. Cellulose is a fascinating solid support that has been used for the immobilization of various ligands. It is a direct-chain macromolecule having an enormous quantity of $-\mathrm{OH}$ groups with $3 \mathrm{AGU}$ (anhydro-glucose)/unit present in the four $-\mathrm{C} 1$ conformations with chemical modification. The extent of the macromolecular cellulosic chain is determined by the quantity of constituents anhydro-glucose units, which differs depending on the basis and dealing of the cellulose(raw) material(Mondal et al., 2020). The cellulose fibers versatility is due to its form, that permits to screw and twist ways other than plane. Due to contact among neighboring cellulose fragments in dehydrated fibers and the existence of $\mathrm{OH}$ (hydroxyl) groups in the chain, strong intermolecular hydrogen bonds were formed (Mondal et al., 2020). Many chemical treatments may be used to boost the water loving or repelling character, structural sturdiness, elasticity, or ion exchange ability, heat resistance, resistance to microbiological attack, while decreasing water retention, among which are those that have had higher or lower elimination of heavy metal ion characteristics.

Cellulose with chelating groups such as quaternary ammonium groups(Liang et al., 2020), thio and amine(Zhang et al., 2017), carboxyl(S.-S. Li et al., 2020), hydroxyl(Hashem et al., 2020), imidazole, and amino(Peng et al., 2020) has been identified as possible aid. The series of modified cellulose-bearing pendant groups such as benzalaniline(Saravanan and Ravikumar, 2015), Pyridine(Saravanan and Ravikumar, 2017), and carboxylic acid(Saravanan and Ravikumar, 2016) that serve as chelating sites for the successful removal of metal ions process are planned with reference to previous work.

Cellulose with benzotriazole chelating groups $(\mathrm{MC}-\mathrm{Tz})$ was synthesized with a chemical modification that included metal-complexing ligands. The chelating agents anchored to polymeric support and the electron donating methyl groups bonded to $\mathrm{N}$, which increases basicity, form an important chelating site for metal ion removal from wastewater. FTIR and ${ }^{13} \mathrm{C}-\mathrm{NMR}$ spectroscopy were used to determine the structure of the Mc-Tz adsorbent. SEM 
was used to determine surface morphology and elemental composition, while Energy Dispersive X-ray was used to determine particle size (EDX). Before and after the chemical equilibration, the AAS (AA6300-Shimada, Japan) was employed to monitor for heavy metal concentration. The experiment was designed for $\mathrm{pH}$, dosage, contact time, and Initial ion strength, to boot. Although the pseudo first-order and second-order rate equations were used, the Langmuir, Freundlich-Peterson, and Temkin models were all used as well. In order to examine the chemical stability and efficiency of the recovery method, experiments were performed using different eluting agents.

\section{EXPERIMENTAL}

\subsection{Materials}

Cellulose (Loba), Sodium meta periodate (Sigma Aldrich), 2-aminotriazole (Sigma Aldrich) were used as received. $\mathrm{CuSO}_{4} 5 \mathrm{H}_{2} \mathrm{O}, \mathrm{Pb}\left(\mathrm{NO}_{3}\right)_{2}, \mathrm{NiSO}_{4} 7 \mathrm{H}_{2} \mathrm{O}, \mathrm{CdSO}_{4} \mathrm{H}_{2} \mathrm{O}$ were procured from BDH chemicals. The solvents such as, N-ethyldimethyl ammonia, DMF, and ethanol were extracted using the standard specified method.

\subsection{Synthesis of Modified Cellulose Bearing Triazole backbone (MC-Tz)}

To prepare derivatives of reactive cellulose, the cellulose was oxidized and functionalized. In addition to that, the dialdehyde cellulose is formed by the periodate oxidation of cellulose( $\mathrm{L}$. Zhang et al., 2020). Following the oxidation of the dialdehyde cellulose, the solution was treated with slightly acidified sodium chlorite. The water-soluble 2,3-dicarboxy cellulose oxidised to over $98 \%$ of its overall oxidation level while the insoluble 2,3-dicarboxy cellulose had just $70 \%$ oxidation. Before the coupling step, the oxidation reaction using $\mathrm{INaO}_{4}$ (sodium metaperiodate) was conducted out on cellulose. This reaction cuts the bond between $\mathrm{C} 2-\mathrm{C} 3$ of the glucosidic ring and transforms the compounds into 2, 3-dialdehydic groups. The Malaprade reaction mechanism is involved in this process(Saravanan and Ravikumar, 2017; Z. Zhang et al., 2020). An aqueous solution of sodium metaperiodate was combined with 
powdered cellulose suspended in distilled water and mixed at laboratory environment in the dark. DAC formed, after completion of reaction, it was separated and neutralized with double distilled water as stated in the procedure. The findings of the survey conducted by (Saravanan and Ravikumar, 2017, 2016) 4 hours at full darkness, under $\mathrm{NaIO}_{4}$ concentrations of $0.01 \mathrm{M}$, thus resulting in 30 carbonyl groups per 100 glucose units(Guggenberger et al., 2020). When a dialdehyde and cellulose are reactivated, they will react with amines to create amine derivatives (Peng et al., 2019; Saravanan and Ravikumar, 2015).

(2-Aminotriazole-dialdehyde- cellulose) was synthesized by condensation of 2-aminotriazole dialdehyde with cellulose. After dissolution of the 2-aminotriazole $(1.5 \mathrm{~g})$ in $20 \mathrm{ml}$ of $\mathrm{N}, \mathrm{N}$ dimethylformamide (DMF), the mixture was diluted with dialdehyde cellulose $(0.5 \mathrm{~g})$ and a few drops of hydrochloric acid (concentrated) was applied as a catalytic agent and stirred at 70 degree Celsius for five hrs, resulting in the catalyst with $\mathrm{MC}-\mathrm{Tz}$ shown in the scheme (Figure 1). The pale yellow is produced by using absolute ethanol to pour in the mixture. After precipitation, the precipitate could cool, separated, and cleaned several times with warm $\mathrm{H}_{2} \mathrm{O}$. Then, it was dried using a vacuum.

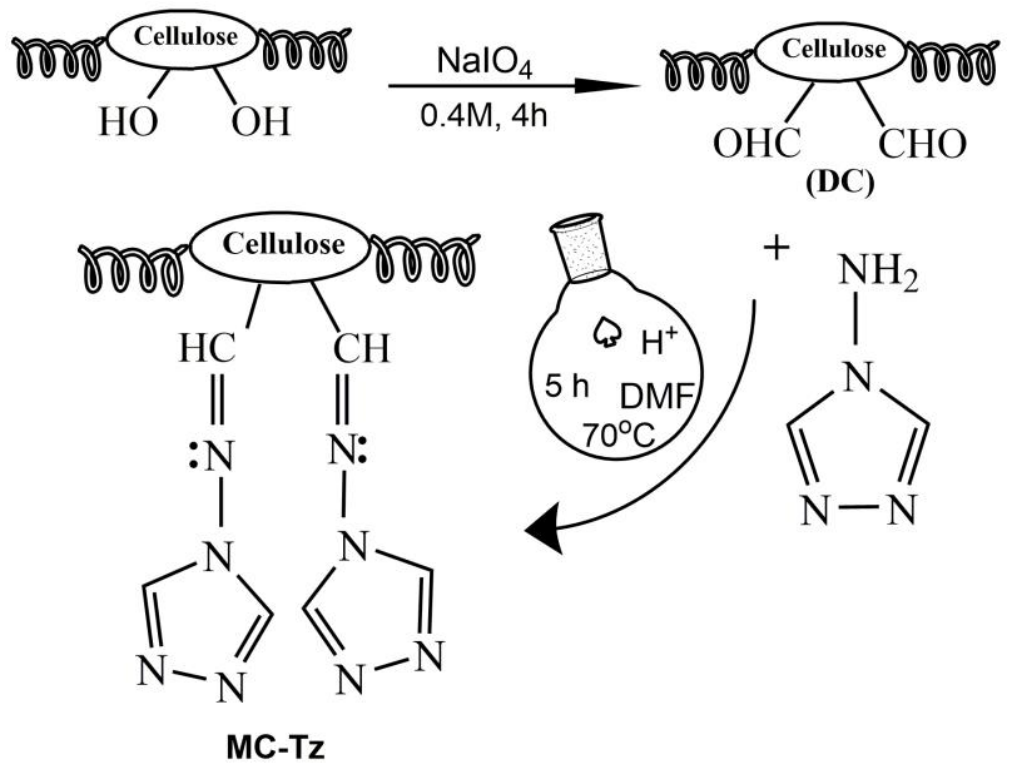

Figure 1. Scheme of MC-Tz 


\section{RESULTS AND DISCUSSION}

\subsection{Spectroscopic studies of MC-Tz}

Metal ions would be strongly adsorbed to the functional groups that exist on chemically modified cellulose. Native cellulose's major peaks: $3348 \mathrm{~cm}^{-1}$ (FT-IR), $2903 \mathrm{~cm}^{-1}(\mathrm{O}-\mathrm{H})$, $1664 \mathrm{~cm}^{-1}$ (C-H ring), $1430 \mathrm{~cm}^{-1}\left(\mathrm{C}-\mathrm{CH}_{2}\right), 1371 \mathrm{~cm}^{-1}$ (C-H bend), and $1058 \mathrm{~cm}^{-1}$ (C-C single bond) (C-O-C). The FTIR spectrum of MC-Tz (Figure 2A) shows the wide and high peak at $3391(\mathrm{O}-\mathrm{H}), 1677$ (-N=CH- azomethine), $1426(\mathrm{C}-\mathrm{N}), 1562(\mathrm{C}-\mathrm{N}), 2362 \mathrm{~cm}^{-1}(\mathrm{C}-\mathrm{H})$ with stretching frequencies of $1,676 \mathrm{~cm}^{-1}(\mathrm{O}-\mathrm{H}), 1,257 \mathrm{~cm}^{-1}$ (N-CH-azomethine), $1,188 \mathrm{~cm}^{-1}$ (C$\mathrm{N})$, and $1,025 \mathrm{~cm}^{-1}(\mathrm{C}-\mathrm{N})$. These frequencies show that a pendent triazole chelating group is present in MC-Tz.
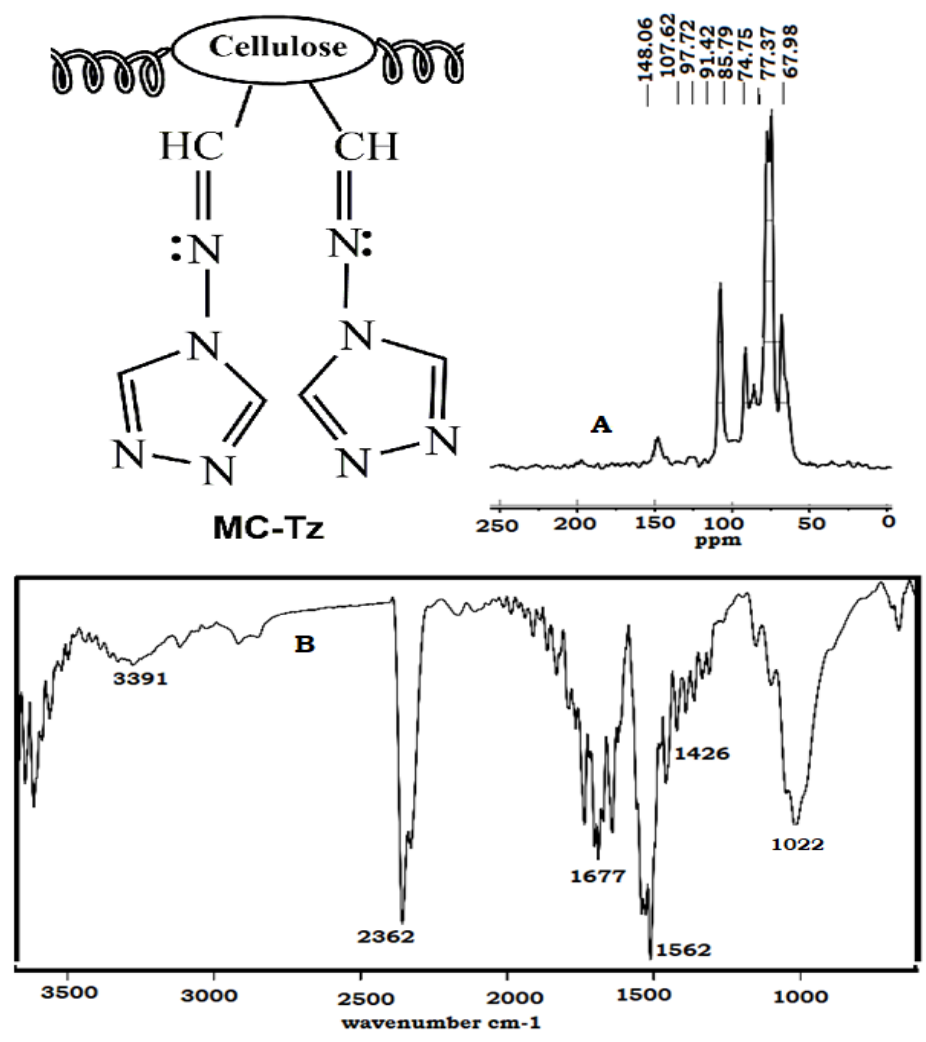

Figure 2. (A) ${ }^{13}$ C CP-MAS NMR and (B) FTIR Spectrum of MC-Tz Adsorption Studies of MC-Tz towards Lead(II), Copper(II), Nickel(II) and Cadmium(II) metal ions. 
${ }^{13} \mathrm{C}$ CP-MAS research inorganic matter Spectrum analysis reveals significant signals for pyranose ring carbons ranging from 62.2 to $102.4 \mathrm{ppm}$, and significant signals for $-\mathrm{CH}_{2}-\mathrm{OH}$ are found between 44.2 and 62.2 ppm(Pettignano et al., 2019; Saravanan and Ravikumar, 2016). Aromatic carbons of the MC-Tz were detected between 67 and $107 \mathrm{ppm}$ in the ${ }^{13} \mathrm{C}$ NMR spectrum (Figure 2B). A wide peak based around the $\delta$ value of 148 ppm was found in the Schiff base carbon, along with the triazole carbon of the pendent chelating group. Based on these results, it is hypothesized that the $\mathrm{MC}-\mathrm{Tz}$ backbone produces triazole pendent classes.

\subsection{Influence of Solution $\mathrm{pH}$}

A major element in the sorption of metal ions on the sorbent is the $\mathrm{pH}$ of the solution. for optimum $\mathrm{pH}$ adsorption, the experiments were performed at $\mathrm{pH}$ 1-9 with $1 \mathrm{~h}$ of equilibration time at $30+1^{\circ} \mathrm{C}$. According to the data in Figure 3a, the highest sorption occurs around $\mathrm{pH} 6$, with reduced metal adsorption occurring at low $\mathrm{pH}$. Adsorbent and adsorbate both have charge, which causes electrostatic repulsion in the acidic region(Kubra et al., 2021). At low $\mathrm{pH}$, the adsorbent's surface was directly linked to hydronium ions $\left(\mathrm{H}_{3} \mathrm{O}^{+}\right)$, which prevent the heavy metal ions from contacting the surface functional group(Binaeian et al., 2020). Expansion of the number of $\mathrm{H}^{+}$ions and metal ions at the $\mathrm{pH}$ of 6.0 occurs due to both ion exchange and complex formation. Beneath $\mathrm{pH} 7$, adsorption analysis could not be conducted. In order to speed up the process, an optimal $\mathrm{pH}$ of 6 was developed for further adsorption experiments. for different adsorbents, comparable optimum $\mathrm{pH}$ for Lead(II), Cadmium(II), and Copper(II) binding has been observed(Kavand et al., 2020).

\subsection{Influence of Adsorbent Dose}

For metal ion removal, the adsorbent dose has a $3 \mathrm{~b}$ curve that increases, and then the curve starts to fall (MC-Tz). The increase in adsorption dose results in an increase in the adsorption 
potential, as there is more active adsorption site surface area and additional sites that are usable for adsorption. This results in an increase in the overall adsorption efficiency of metal ions, and hence the adsorption capacity increases from $8 \mathrm{~g} / \mathrm{L}$ of the $\mathrm{MC}-\mathrm{Tz}$ adsorbent. Although the equilibrium between the metal ions and the adsorption sites was nearly reached, there was no appreciable further reduction in the metal ion concentration.

\subsection{Modeling -Effect of Agitation time}

Adsorption processes such as mass transfer and chemical reaction, such as Intra particle diffusion and Elovich kinetic models, have been analyzed by using the pseudo-firstorder, pseudo-second order, and the Intra particle diffusion and Elovich kinetic models. The kinetic activity of the sorbent (MC-Tz) towards the metal ions was investigated by calculating adsorption on a contact time scale. A longer agitation time results in an increase in the boundary layer resistance, and this results in a decrease in the ions mobility. As a result, the ions' kinetic energy is improved, allowing for greater adsorption. Adsorbate residence time is inversely proportional to the metal ion adsorption rate, which is determined by the metal's behavior and the adsorbent's efficiency.

One continuous curve, as if covering a monolayer of metal ions, portrays a single, flat, and nearly instantaneous rate of absorption, with equilibrium reached at a certain point in time regardless of initial concentrations. The results obtained in the present study were compiled into Table 1 in the form of the pseudo-first order rate constant, $\mathrm{k}_{\mathrm{ad}}$, and correlation coefficients for different concentrations of the Lead(II), Copper(II) and Nickel(II) and Cadmium(II) metal ions. The estimated correlation coefficient value varies greatly from the experimentally observed one, showing a weak pseudo first-order fit to the experimental results. 
For Lead(II), Copper(II) and Nickel(II) and Cadmium(II), the pseudo-second-order kinetic model is studied, and the following plot is made: [t(qt)/q] versus [t]. The value of $\mathrm{q}_{\mathrm{e}}$, $\mathrm{k}$, and $\mathrm{R}^{2}$ can be found from the slope and intercept. If this form is true to a pseudo secondorder model, the linearized plot should follow a straight line. One piece of evidence that shows a link between the t/qt (or t) versus $t$ plot for the pseudo-second order model for the Lead(II), Copper(II), and Nickel(II) and Cadmium(II) metal ions is that these plots yield strikingly straight lines (correlation coefficient, $\mathrm{R}^{2}>0.99$ ). Additionally, $\mathrm{q}_{\mathrm{e}} \mathrm{s}$ theoretical values coincide with the experimental value extremely well. While these facts support the hypothesis that adsorption of Lead(II), Copper(II), Nickel(II) and Cadmium(II) metal ions by MC-Tz follows the pseudo-second-order kinetic model, which implies that Chemisorption is the rate-limiting step, it should be noted that the latter theory has not been proven in all cases.

In Chemisorption, metal ions bind to the adsorbent surface by forming a chemical (usually covalent) bond and congregate in areas where there are the most coordination sites(Xie et al., 2020). There is a direct relationship between the concentration of metal ions in the solution and the possibility of collisions among these species. The faster at Lead(II), Copper(II), Nickel(II) and Cadmium(II) metal ions bind to the surface of the adsorbent, the lower the concentration of metal ions in the solution(Chen et al., 2020).

Typical is fitting the kinetic data to the intra-particle diffusion model when an approach to find out the rate-limiting step. Since each of these heavy metal ions (Lead(II), Copper(II), and Nickel(II) and Cadmium(II)) shows the same type of plot with differing characteristics, it can be concluded that transport of heavy metal ions from solution through the particle solution interface, and the pores of the particle, all proceed in a nearly identical manner. When extrapolating the linear part of the plot to the axis, one obtains the intercepts, which are proportional to the thickness of the boundary layer, or the larger the intercept, the greater is the boundary layer effect(El Gamala et al., 2020). 
Elovich equation describes the heterogeneous distribution of adsorption due to heterogeneous chemisorption kinetics. Data provided in the current study indicates a correlation coefficient of $93 \%$ or higher indicates that the Chemisorption process refers to the ion exchange reaction.
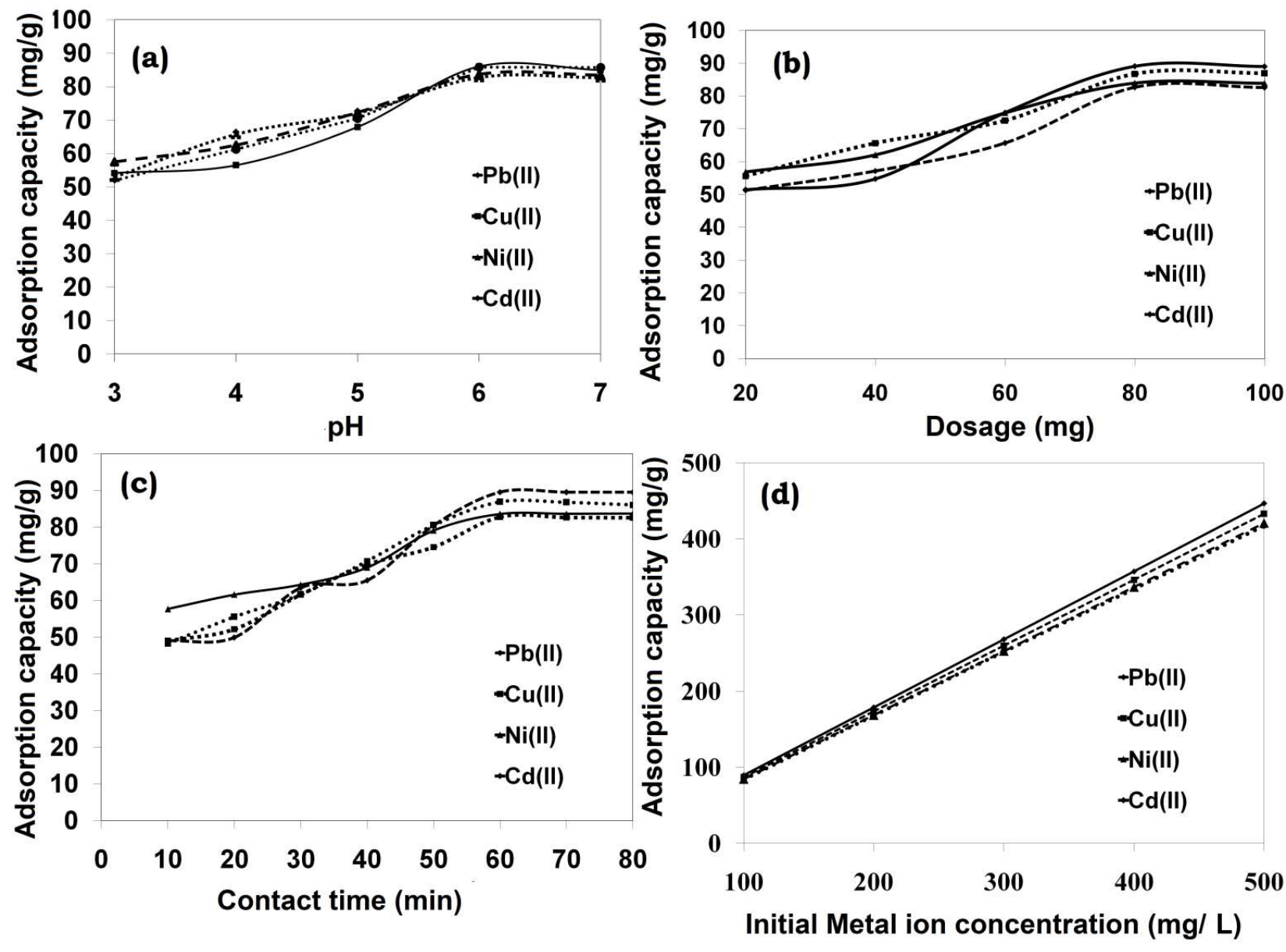

Figure 3. Effect of Adsorption parameters

\subsection{Adsorption Isotherm}

\subsubsection{Effect of initial metal ion concentration}

Metals are taken up by the adsorbent, which can be represented by the isotherm model of Langmuir, Freundlich, Redlich-Peterson, and Temkin, as shown in Figure $3 \mathrm{~d}$ and as shown in the results in Table 2. In sorption equilibrium studies, adsorbate distribution, 
adsorbent heterogeneity, adsorbent coverage, and adsorbent interaction are defined. Maximal adsorption is usually occurring when a saturated monolayer of the molecules is on the adsorbent. When a constant solute molecule is present, the adsorption energy is present in all areas.

Since the adsorbate molecules are in constant motion, it is impossible to shift them toward the surface. The maximum adsorption capacity for the solid phase loading and the heat of adsorption defined by the Langmuir constants $\mathrm{qm}$ and $\mathrm{K}_{\mathrm{L}}$ is equal to the maximum adsorption capacity of the fluid phase loading and the temperature of adsorption. $\mathrm{R}_{\mathrm{L}}$ values illustrate the adsorption mechanism because $R_{L}>1$ indicates unfavorable adsorption, $R_{L}=1$ portrays linear adsorption, and $\mathrm{R}_{\mathrm{L}}<1$ reflects favorable adsorption(Nadir et al., 2021). The graphical data shown in Figure 4 shows that the Langmuir equation matches the isotherm data very well $\left(\mathrm{R}^{2}=0.997\right)$. The values of $\mathrm{q}_{\mathrm{m}}$ and $\mathrm{R}_{\mathrm{L}}$ for Lead(II), Copper(II), Nickel(II), and Cadmium(II) were found to be 453.2, 485.5, 473.2, and $455.6 \mathrm{mg} / \mathrm{g}$ and $0.0205,0.01050$, 0.0148 , and $0.01221 / \mathrm{mg}$. That is, the mechanism of adsorption was depicted as favorable. Ionic radii may be the reason for this preferential sorption conduct. Ionic radii are highest for Lead(II) $\left(1.19^{\circ}\right)$ and then decrease as the other cations have smaller sizes: Cadmium(II) $\left(0.97^{\circ}\right)$, Nickel(II) $\left(0.72^{\circ}\right)$, and Copper(II) $\left(0.69^{\circ}\right)$. The greater the ionic radius, the weaker the ionic binding and the water phase because of the smaller hydration potential of that ion. Due to the fact that Lead(II) and Cadmium(II) have a higher hydration energy than Nickel(II) and Copper(II), adsorption preference may be present for Lead(II) and Cadmium(II) as well(Dev et al., 2020).

Metal ion adsorption potential $\left(\mathrm{q}_{\mathrm{e}}\right)$ for a given mass of adsorbent is well-defined by Freundlich isotherm model and evaluated for metal ion concentrations at equilibrium $(\mathrm{Ce})$. Adsorption yields of the Freundlich constants $\mathrm{K}_{\mathrm{f}}$, which are 35.09, 25.59, 28.46, and 22.71 for Lead(II), Copper (II), Nickel (II), and Cadmium(II), were found to be favorable and their 
values for $\mathrm{n}$ were $2.2,1.9,2.1$, and 2 respectively. The $\mathrm{R}^{2}$ values of Cadmium(II), Copper(II), Lead(II), and Nickel(II) explain why the Freundlich model was generated in the order of Cadmium(II) $>$ Copper(II) $>$ Lead(II) $>$ Nickel (II).

Langmuir and Freundlich characteristics involve both homogeneous and heterogeneous structures, which refer to the heavy metal ion adsorption mechanism with the Redlich Isotherm model. The Redlich-Peterson isotherm exponent between 0 and $1, \beta$, is defined as $\beta$. For equivalent values of $\beta$, the Langmuir isotherm is the better. Otherwise, the Freundlich isotherm is the better. When adsorbing Lead(II), Copper(II), and Nickel(II) ions onto the MC-Tz adsorbent, the results show that the adsorption constant, $\beta$, is close to 1 , suggesting that Lead(II), Copper(II), and Cadmium(II) ions have strong isotherms while Nickel(II) ions have worse ones. Lead (II) is adsorbed last based on the $\mathrm{R}^{2}$ values because the adsorption of the other metals goes from the least to most expensive.

The assumptions made in constructing the Temkin isotherm are that all molecules in the layer undergo a linear decrease in heat of sorption as a result of sorbate-sorbent interactions, and the amount of heat of sorption decrease is proportional to the degree of coverage. B, which represents the constant of adsorption in this isotherm, can be defined by the universal gas constant $\left(\mathrm{J} \mathrm{mol}^{-1} \mathrm{~K}^{-1}\right), \mathrm{R}$ is the universal gas constant $\left(\mathrm{J} \mathrm{mol}^{-1} \mathrm{~K}^{-1}\right), \mathrm{T}$ is the temperature $(\mathrm{K}), \mathrm{b}$ is the variation of adsorption energy $\left(\mathrm{J} \mathrm{mol}^{-1}\right)$, and the equilibrium binding constant $\left(\mathrm{mg}^{-1}\right)$ that corresponds to the maximum binding energy. Applying $\mathrm{Q}_{\mathrm{e}}$ to the plot of $\operatorname{lnC} \mathrm{C}_{\mathrm{e}}$ vs. $\ln$ results in the determination of the isotherm constants $\mathrm{B}$ and $\mathrm{KT}$. B $<20 \mathrm{~kJ} / \mathrm{mol}$. This highlights weak interaction between the metal ions and sorbent (MC-Tz), facilitating ion exchange. In the Temkin isotherm model, the metal ions are ordered according to the $\mathrm{R}^{2}$ values: Lead (II) > Copper (II) > Cadmium(II) > Nickel (II). The high electro negativity and high softness value of Lead(II) is conducive to this, as it adsorbs over the Copper(II) and Nickel(II) on the binding sites of the MC-Tz. 

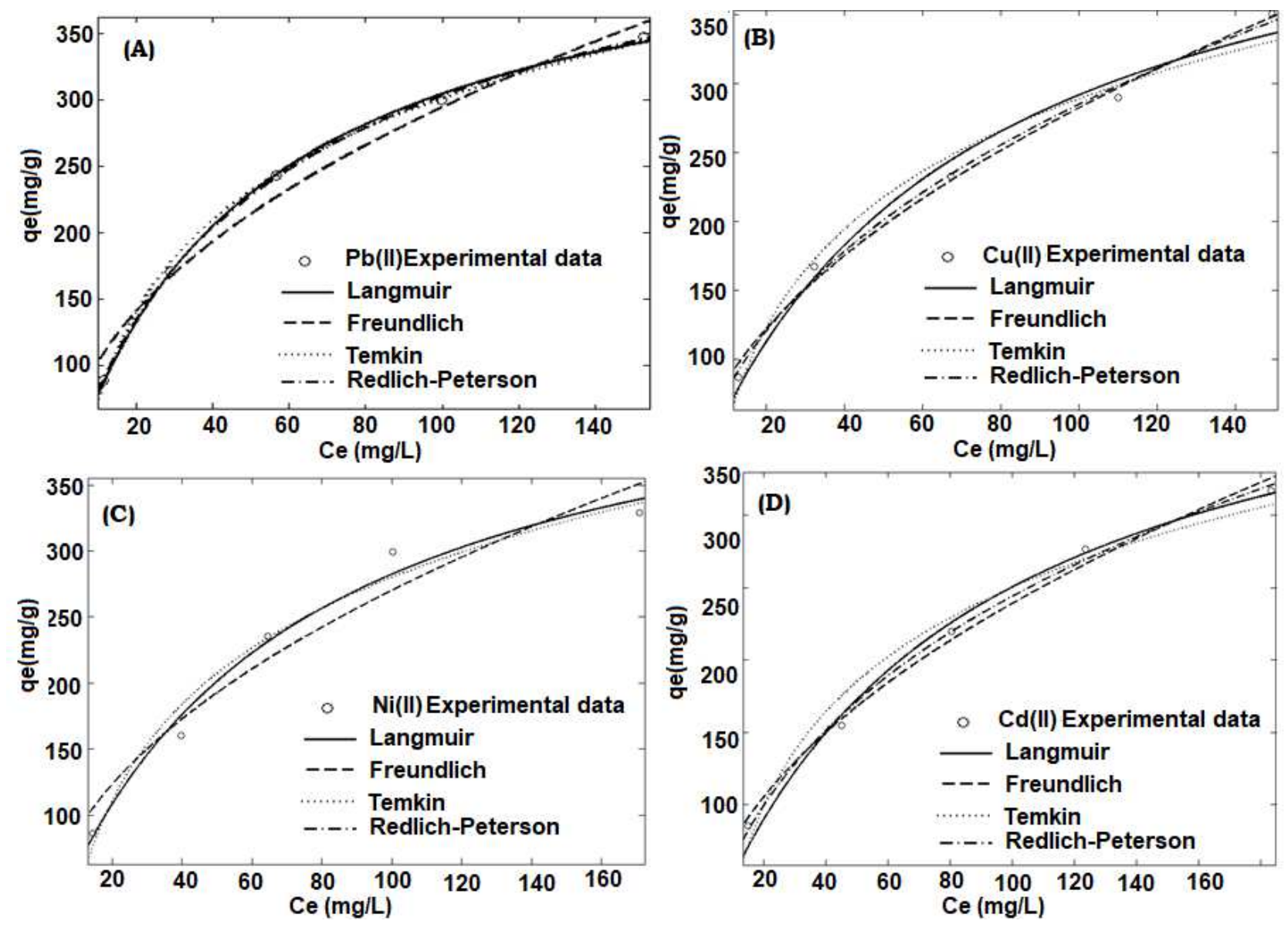

Figure 4. Non-linear adsorption isotherm for (A) Lead(II) (B) Copper(II) (C) Nickel(II) and (D)Cadmium(II) ions with MC-Tz

\subsection{Thermodynamic Study}

Depending on the temperature used, the adsorption equilibrium can either be exothermic or endothermic. Inflating the adsorbate's sorption potential increases with the rise in temperature, as the pore size of the adsorbent and the adsorbent surface are now becoming larger. In Table 3 , it is observed that the Gibbs free energy shift ( $\Delta G^{\circ}$ ) is small and negative $\Delta S^{n}$ but increases with increased temperature, which means that the adsorption mechanism is thermodynamically unfavorable. The randomness of metal adsorbent solution interface during the adsorption indicates by the negative value of When the negative value of $\left(\Delta H^{\alpha}\right)$ is taken into consideration, it can be inferred that metal ion adsorption is an exothermic operation. the MC-Tz adsorbent was shown to be efficient for the removal of metal ions such 
as Lead(II), Copper(II), Nickel(II), and Cadmium(II) from aqueous solutions by the above observations.

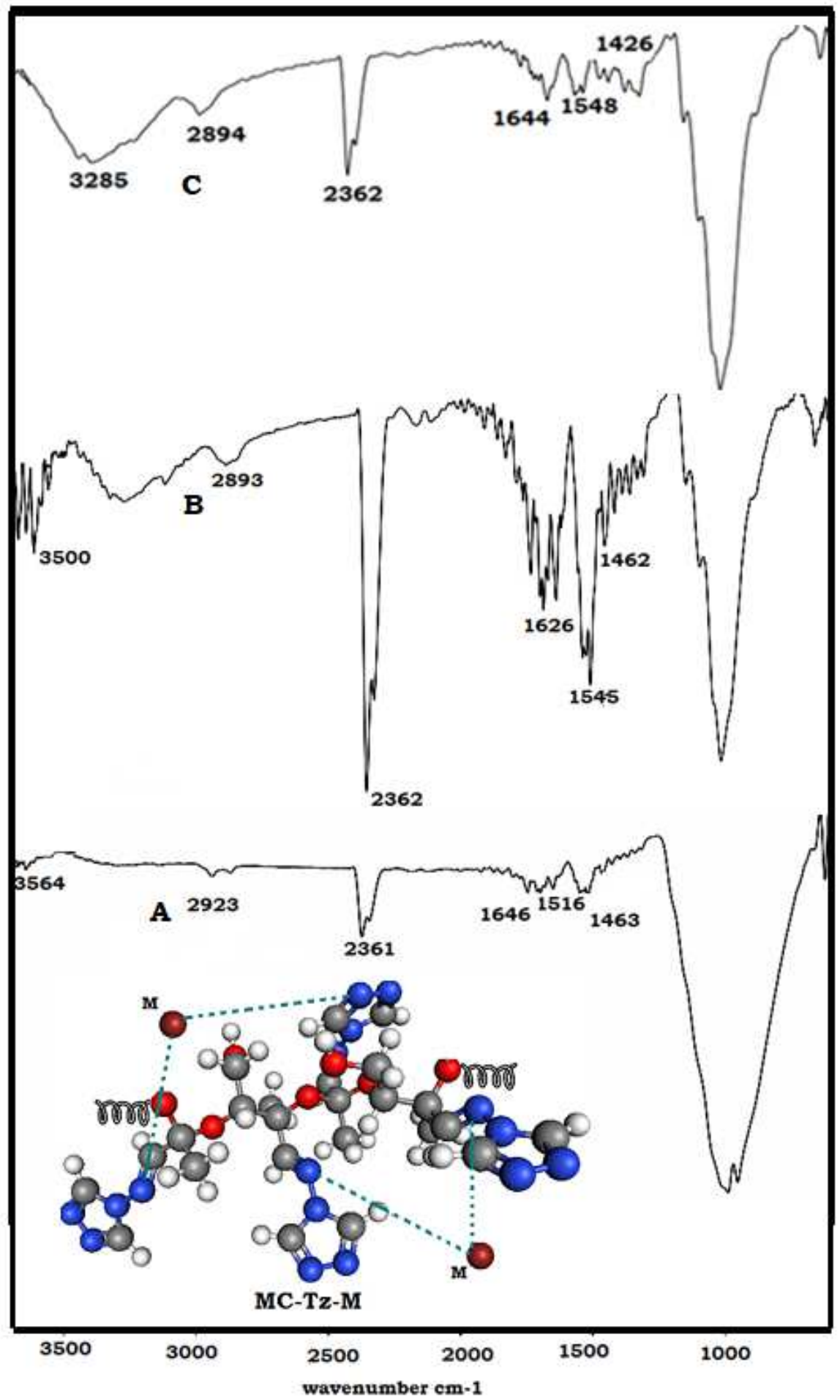

Figure 5. FTIR Spectrum of (A) MC-Tz-Pb, (B) MC-Tz-Ni and (C) CMC-Bz-Cd. 


\subsection{Complexation Mechanism}

Reduced bond strength was caused by the complexation of MC-Tz with Lead(II), Nickel(II) and Cadmium(II) metal ions, which resulted in a major stretching frequency change, which started at $1677 \mathrm{~cm}^{-1}(-\mathrm{CH}=\mathrm{N}$ - stretching) and ended at 1646, 1626, and 1644 $\mathrm{cm}^{-1}$. the C-N peak in the metal-chelated MC-Tz changed from $1562 \mathrm{~cm}^{-1}$ to 1516,1545 , and $1548 \mathrm{~cm}^{-1}$ (Figure 5). Furthermore, the metal chelated MC-Tz was found to have a drastically different shape and strength. The following discussion is based on the explanations above and recommends that the chelating groups such as $-\mathrm{CH}=\mathrm{N}-,-\mathrm{OH}$, and $\mathrm{C}-\mathrm{N}$ should be considered the primary binding sites for metal ions as shown in Figure 5.

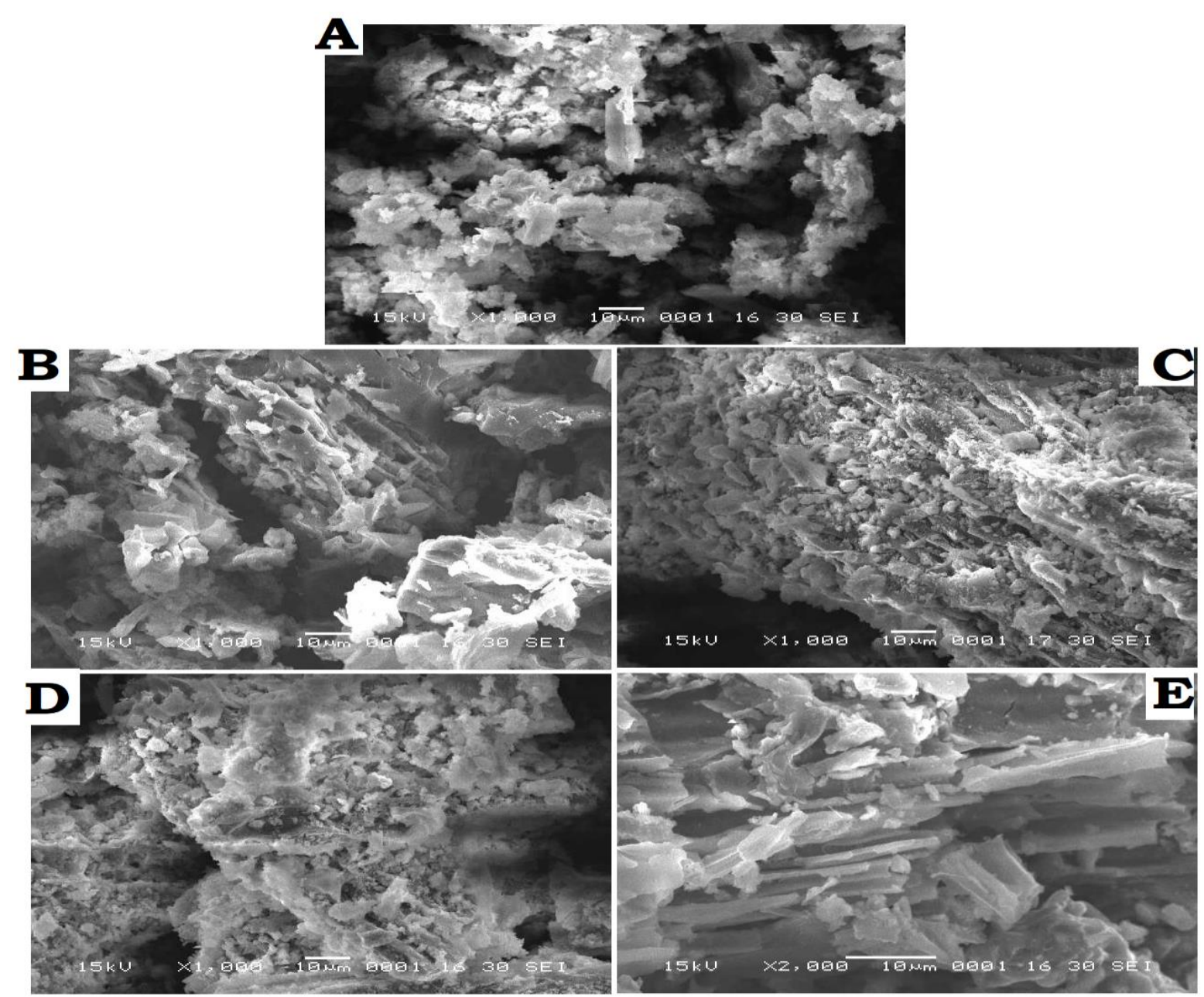

Figure 6. SEM morphology of (A) MC-Tz (B) Lead(II) (C) Copper(II) (D)

Nickel(II) and (E)Cadmium(II) ions metal loaded CMC-Bz. 
In Figure 6, a SEM image of the surface morphology of the MC-Tz, Lead(II), Copper(II), Nickel(II), and Cadmium(II) metal ions loaded MC-Tz is shown. The surface shown in the SEM micrographs is non-particulate and coated in folds. The surface of the polymer mat is rough, creating more gaps that allow the metal solution to mix more easily with the solution, resulting in better metal adsorption. When the metal ions adsorb to the functional group inside the wall of the polymeric region, the surface texture and pore development change. Grooves are less prominent in the SEM micrograph of MC-Tz after metal adsorption because of the Lead(II), Copper(II), Nickel(II) and Cadmium(II) particles adsorbed.

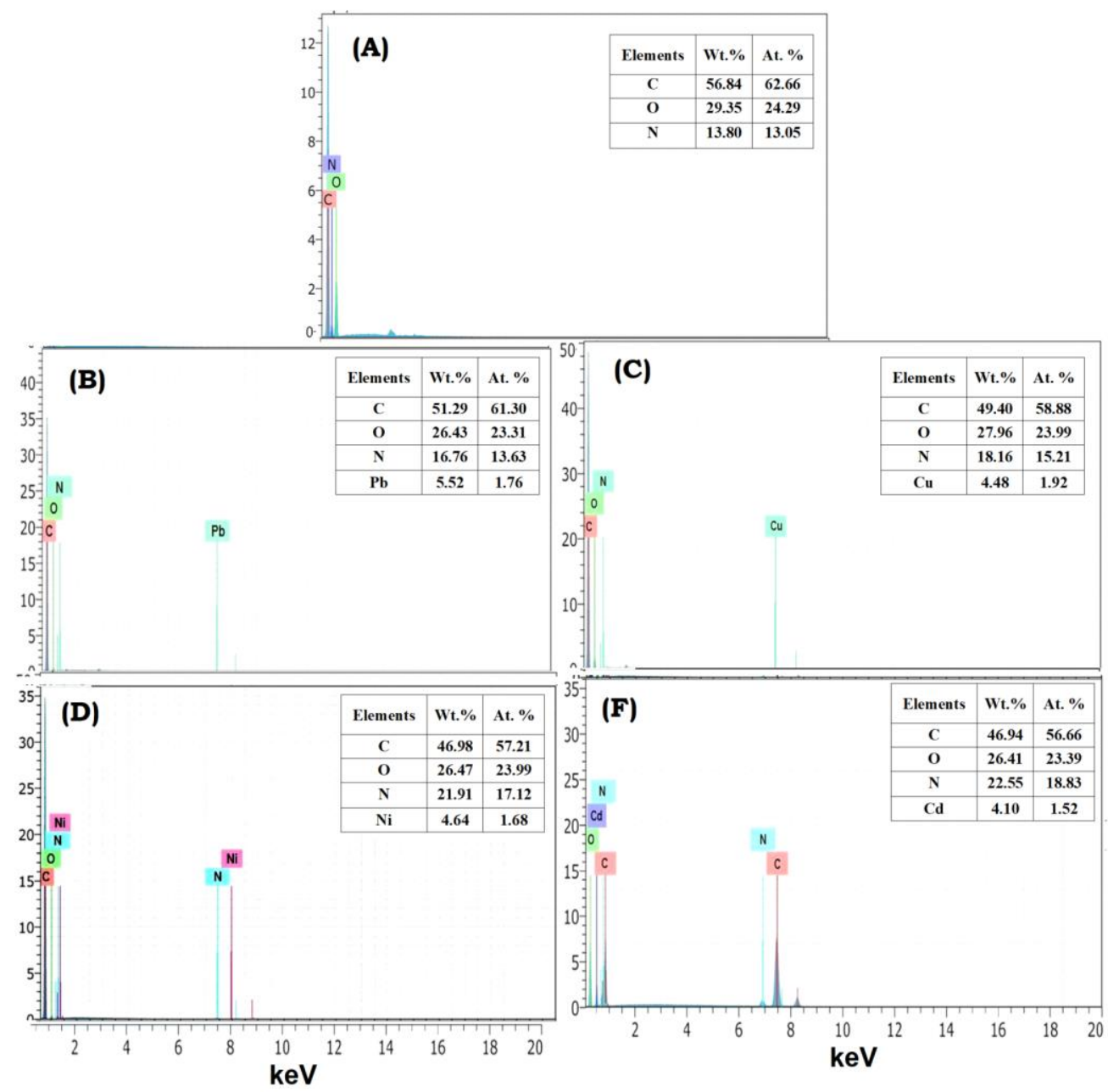

Figure 7. EDAX spectra of (A) MC-Tz (B) MC-Tz-Lead(II) (C) MC-TzCopper(II) (D) MC-Tz-Nickel(II) and (E) MC-Tz-Cadmium(II) 
EDX spectra of the metal ions Lead(II), Copper(II), Nickel (II), and Cadmium(II) that were applied (Figure 7). There are only C, N, and O peaks present in the EDX spectrum of MC-Tz. N content of $13.80 \mathrm{wt} \%$ indicates the successful adsorption mechanism, the Schiff base with amino triazole groups is followed by further experiments.
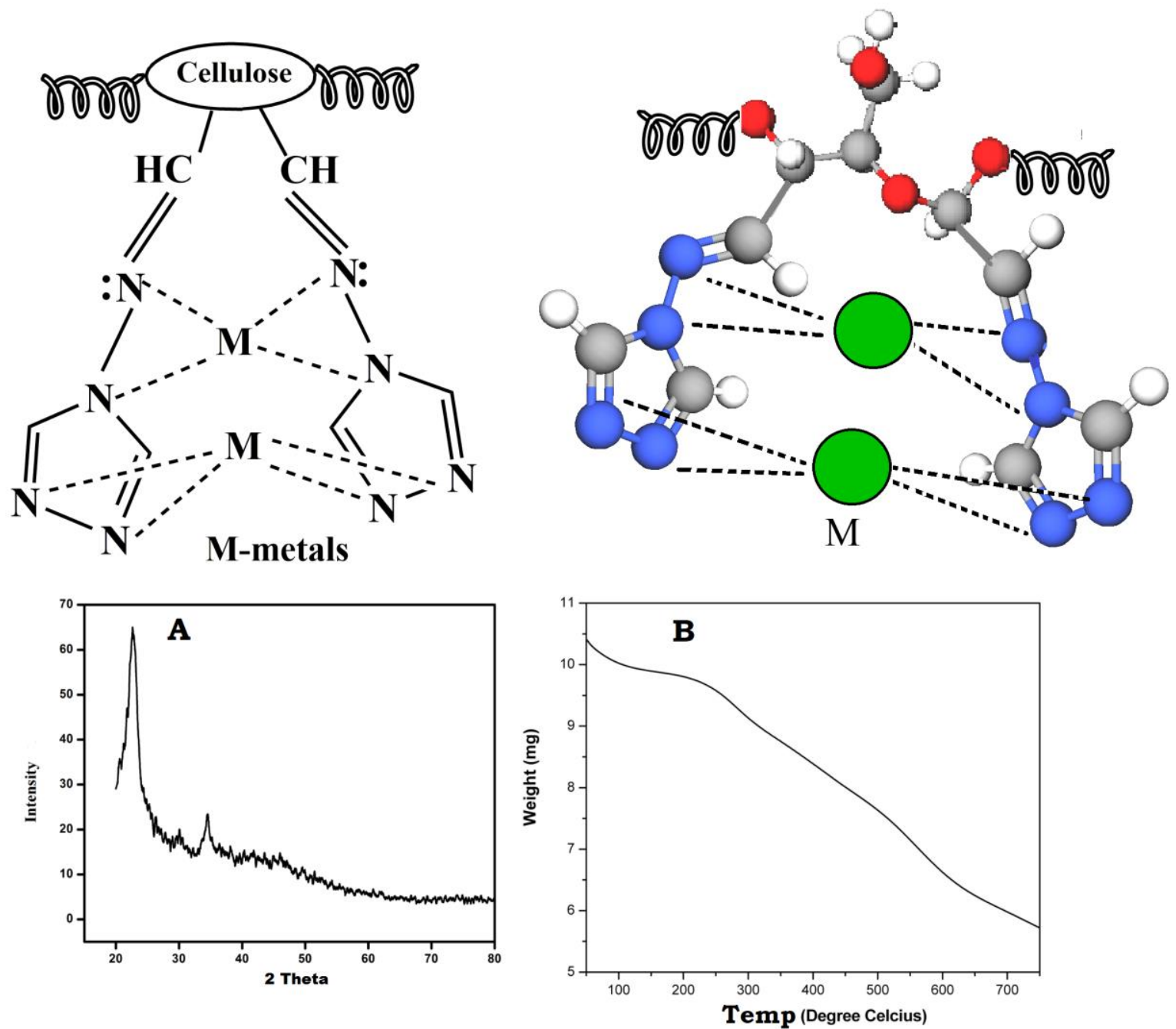

Figure 8. XRD pattern and TGA curve of MC-Tz

Figure 8A shows the XRD patterns of the chemically modified MC-Tz, which shows the amorphous nature due to the large size of the adsorbent chains. When observing the long, polymeric peaks, it is evident that the amorphous nature of the MC-Tz polymeric adsorbent 
makes it perfect for Lead(II), Copper(II) and Nickel(II) and Cadmium(II) metal ion adsorption. TGA was used to investigate the thermal stability and degradation behavior of the MC-Tz by rapidly heating and cooling the sample to $60^{\circ} \mathrm{C}$ and $10^{\circ} \mathrm{C} / \mathrm{min}$. Figure $8 \mathrm{~B}$ shows the TGA curves for this test. According to one hypothesis, the first stage of decomposition, to about $200^{\circ} \mathrm{C}$, was triggered by dehydration and volatilization processes, and the next stage, about $15 \%$ weight loss, occurred between $220^{\circ} \mathrm{C}-340^{\circ} \mathrm{C}$ in MC-Tz. This furthers the results from the MC-Tz show the strong thermal stability, and the components can be used up to $250^{\circ} \mathrm{C}$. Table 4 identifies the adsorbent known as the $\mathrm{MC}-\mathrm{Tz}$ and compares it to other recorded materials. This study shows that metal ions minimize the thermodynamic stability of this substance.
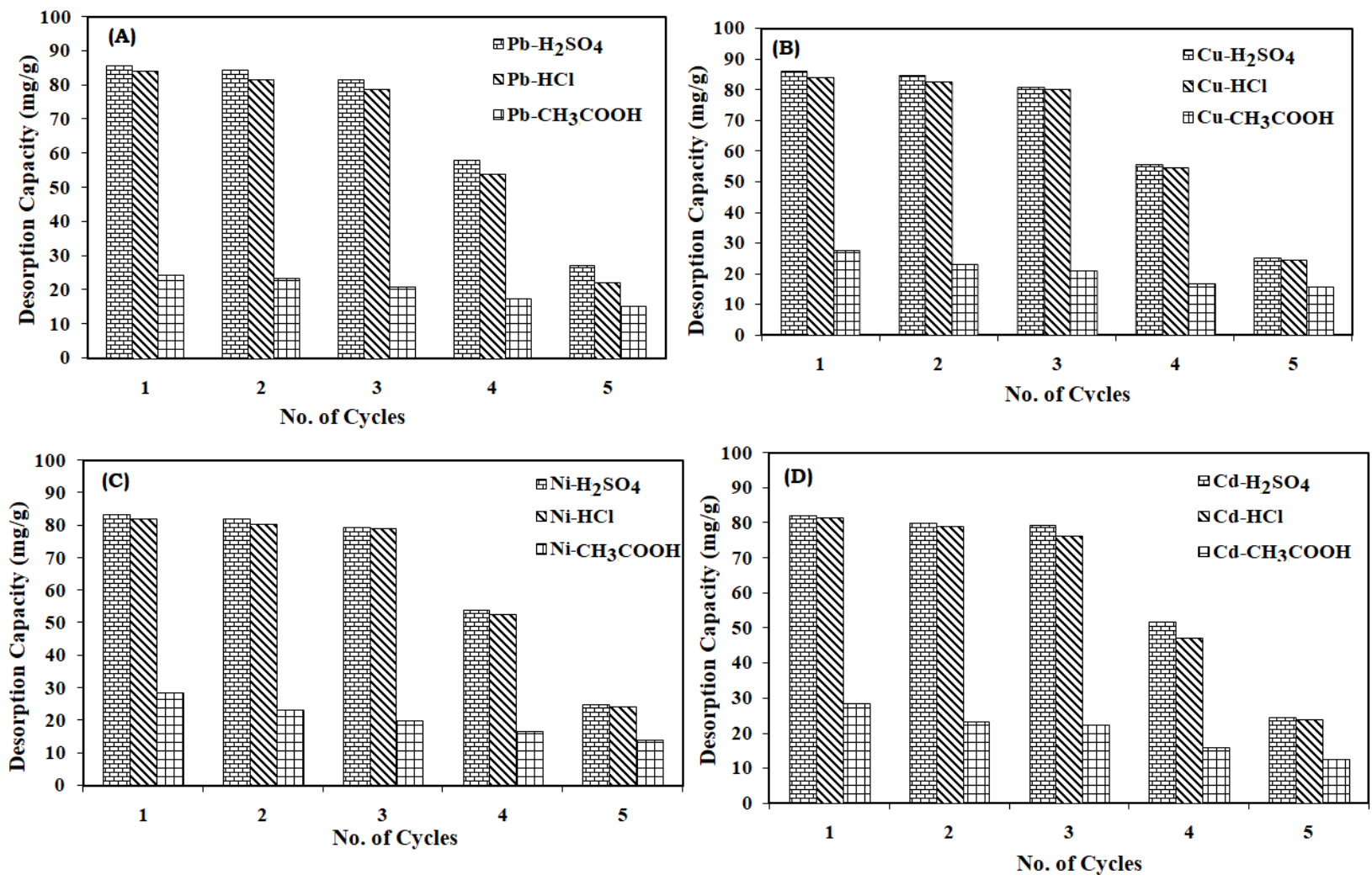
Figure 9. Recyclability of (A) Lead(II)
(B) Copper(II) (C) Nickel(II) and (D)Cadmium(II) ions onto MC-Tz 


\subsection{Desorption and Regeneration studies}

It is essential that the adsorbent is easily regenerated, and the desorbing agent is effective, inexpensive, non-polluting, and non-damaging. For the desorption efficiency shown in Figure 9, a concentration of $0.1 \mathrm{M} \mathrm{HCl}, \mathrm{H}_{2} \mathrm{SO}_{4}$, and $\mathrm{CH}_{3} \mathrm{COOH}$ was used. It is also evident from the results that after numerous regeneration and reuse cycles, the novel poly adsorbent MC-Tz are still successful.

\section{CONCLUSION}

Environmental issues have caused a substantial amount of research into industrial adsorbents. Considering this, we created a new, low-cost sorbent that is made from cellulose, which is abundant, biodegradable, and structurally stable. Incorporating polymeric chelating moieties that contain a variety of different $\mathrm{O}, \mathrm{N}, \mathrm{S}$, and $\mathrm{P}$ donor atoms into the cellulose backbone results in the high extraction efficiency for metals from aqueous solutions. In addition to a main band shift, there is a distinct shift in the primary stretching frequencies for $-\mathrm{C}=\mathrm{N}-,-\mathrm{C}-\mathrm{N}-,-\mathrm{N}=\mathrm{N}-$ and $-\mathrm{CH}=\mathrm{N}$ - classes in the FTIR spectrum. These heteroatoms can be bound to the metal ions by coordination bonds. The greater probability of bond formation is further shown by the lack of chemical resistance to metal ions when using a $0.1 \mathrm{~N}_{2} \mathrm{SO}_{4}$ solution. As a potent adsorbent, the chemically modified $\mathrm{Mc}-\mathrm{Tz}$ adsorbs a wide range of $\mathrm{pH}$ values and demonstrates good activity over a broad $\mathrm{pH}$ range, with adsorption isotherm and adsorption kinetic data fitting the pseudo-second-order model. By conducting thermodynamic experiments, the feasibility and exothermic design of the adsorption method is thoroughly developed. These treated wastewater samples show a strong application opportunity and important future research potential in heavy metal adsorbent research. 


\section{References:}

[1] Binaeian, E., Esfandyari, A., Valipour, P., Hoseinpour Kasgary, A., Afrashteh, S., 2020. Cadmium cation uptake through amine and acid post-functionalized Santa Barbara Amorphous materials; comprehensive adsorption studies. Environ. Prog. Sustain. Energy e13548.

[2] Briffa, J., Sinagra, E., Blundell, R., 2020. Heavy metal pollution in the environment and their toxicological effects on humans. Heliyon 6, e04691.

[3] Chen, Y., Zhao, W., Zhao, H., Dang, J., Jin, R., Chen, Q., 2020. Efficient removal of Lead (II), Cadmium(II), Copper (II) and Nickel (II) from aqueous solutions by tetrazolebonded bagasse. Chem. Phys. 529, 110550.

[4] Dev, V.V., Baburaj, G., Antony, S., Arun, V., Krishnan, K.A., 2020. Zwitterion-chitosan bed for the simultaneous immobilization of Zn (II), Cadmium(II), Lead (II) and Copper (II) from multi-metal aqueous systems. J. Clean. Prod. 255, 120309.

[5] El Gamala, M., Mohamedb, F.M., Mekewic, M.A., Hashemc, F.S., El-Aassard, M.R., Khalifae, R.E., 2020. Adsorptive removal of Methyl orange from aqueous solutions by polyvinylidene fluoride tri-flouro ethylene/carbon nanotube/kaolin nanocomposite: kinetics, isotherm, and thermodynamics. Desalin Water Treat 193, 142-151.

[6] Gromadzka, G., Tarnacka, B., Flaga, A., Adamczyk, A., 2020. Copper Dyshomeostasis in Neurodegenerative Diseases-Therapeutic Implications. Int. J. Mol. Sci. 21, 9259.

[7] Guggenberger, M., Hettegger, H., Zwirchmayr, N.S., Hosoya, T., Bacher, M., Zaccaron, S., Böhmdorfer, S., Reiter, H., Spitzbart, M., Dietz, T., 2020. Degradation of the cellulosic key chromophore 2, 5-dihydroxy-[1, 4]-benzoquinone (DHBQ) under conditions of chlorine dioxide pulp bleaching: formation of rhodizonate as secondary chromophore - a combined experimental and theoretical study. Cellulose 1-27.

[8] Hashem, M.A., Elnagar, M.M., Kenawy, I.M., Ismail, M.A., 2020. Synthesis and application of hydrazono-imidazoline modified cellulose for selective separation of precious metals from geological samples. Carbohydr. Polym. 237, 116177.

[9] Kavand, M., Eslami, P., Razeh, L., 2020. The adsorption of cadmium and lead ions from the synthesis wastewater with the activated carbon: optimization of the single and binary systems. J. Water Process Eng. 34, 101151.

[10] Kubra, K.T., Salman, M.S., Hasan, M.N., 2021. Enhanced toxic dye removal from wastewater using biodegradable polymeric natural adsorbent. J. Mol. Liq. 328, 115468.

[11]Li, S.-S., Wang, X.-L., An, Q.-D., Xiao, Z.-Y., Zhai, S.-R., Cui, L., Li, Z.-C., 2020. Upon designing carboxyl methylcellulose and chitosan-derived nanostructured sorbents for efficient removal of Cadmium(II) and Cr (VI) from water. Int. J. Biol. Macromol. 143, 640-650.

[12]Li, X., Li, R., Yan, J., Song, Y., Huo, J., Lan, Z., Chen, J., Zhang, L., 2020. Co-exposure of cadmium and lead on bone health in a southwestern Chinese population aged 40-75 years. J. Appl. Toxicol. 40, 352-362.

[13]Liang, X., Liang, B., Wei, J., Zhong, S., Zhang, R., Yin, Y., Zhang, Y., Hu, H., Huang, Z., 2020. A cellulose-based adsorbent with pendant groups of quaternary ammonium and amino for enhanced capture of aqueous Cr (VI). Int. J. Biol. Macromol. 148, 802-810.

[14] Mondal, S., Das, S., Nandi, A.K., 2020. A review on recent advances in polymer and peptide hydrogels. Soft Matter 16, 1404-1454.

[15] Nadir, I., Achour, Y., El Kassimi, A., El Himri, M., Laamari, M.R., El Haddad, M., 2021. Removal of Antibiotic Sulfamethazine from Aqueous Media. Phys. Chem. Res. 9, $165-180$. 
[16] Obasi, P.N., Akudinobi, B.B., 2020. Potential health risk and levels of heavy metals in water resources of lead-zinc mining communities of Abakaliki, southeast Nigeria. Appl. Water Sci. 10, 1-23.

[17]Peng, X., Liu, P., Pang, B., Yao, Y., Wang, J., Zhang, K., 2019. Facile fabrication of pHresponsive nanoparticles from cellulose derivatives via Schiff base formation for controlled release. Carbohydr. Polym. 216, 113-118.

[18]Peng, X., Yan, Z., Hu, L., Zhang, R., Liu, S., Wang, A., Yu, X., Chen, L., 2020. Adsorption behavior of hexavalent chromium in aqueous solution by polyvinylimidazole modified cellulose. Int. J. Biol. Macromol. 155, 1184-1193.

[19] Pettignano, A., Charlot, A., Fleury, E., 2019. Carboxyl-functionalized derivatives of carboxymethyl cellulose: Towards advanced biomedical applications. Polym. Rev. 59, 510-560.

[20] Saravanan, R., Ravikumar, L., 2017. Renewable modified cellulose bearing chelating schiff base for adsorptive removal of heavy metal ions and antibacterial action. Water Environ. Res. 89, 629-640.

[21] Saravanan, R., Ravikumar, L., 2016. Cellulose bearing Schiff base and carboxylic acid chelating groups: a low cost and green adsorbent for heavy metal ion removal from aqueous solution. Water Sci. Technol. 74, 1780-1792.

[22] Saravanan, R., Ravikumar, L., 2015. The use of new chemically modified cellulose for heavy metal ion adsorption and antimicrobial activities. J. Water Resour. Prot. 7, 530.

[23] Xie, X., Zhao, X., Luo, X., Su, T., Zhang, Y., Qin, Z., Ji, H., 2020. Mechanically activated starch magnetic microspheres for Cadmium(II) adsorption from aqueous solution. Chin. J. Chem. Eng.

[24]Zhang, C., Su, J., Zhu, H., Xiong, J., Liu, X., Li, D., Chen, Y., Li, Y., 2017. The removal of heavy metal ions from aqueous solutions by amine functionalized cellulose pretreated with microwave-H 2 O 2. RSC Adv. 7, 34182-34191.

[25]Zhang, L., Yan, P., Li, Y., He, X., Dai, Y., Tan, Z., 2020. Preparation and antibacterial activity of a cellulose-based Schiff base derived from dialdehyde cellulose and L-lysine. Ind. Crops Prod. 145, 112126.

[26]Zhang, Z., Liu, G., Li, X., Zhang, S., Lü, X., Wang, Y., 2020. Design and synthesis of fluorescent nanocelluloses for sensing and bioimaging applications. ChemPlusChem. 
Figures

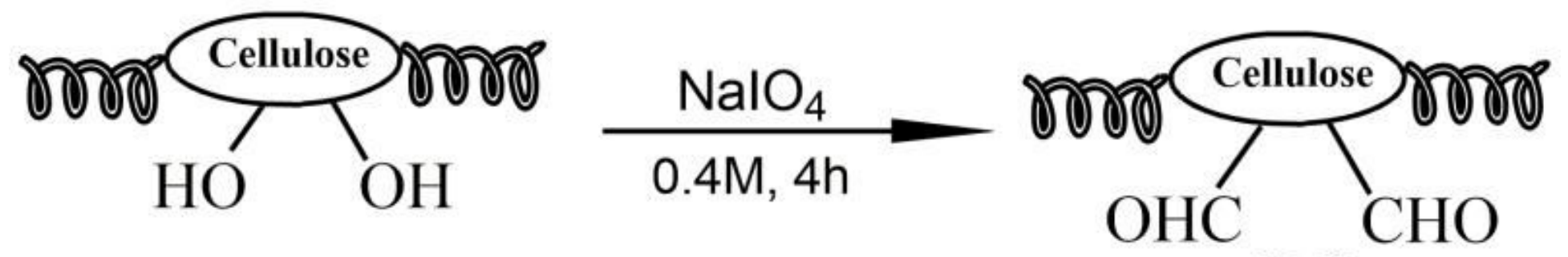

(DC)

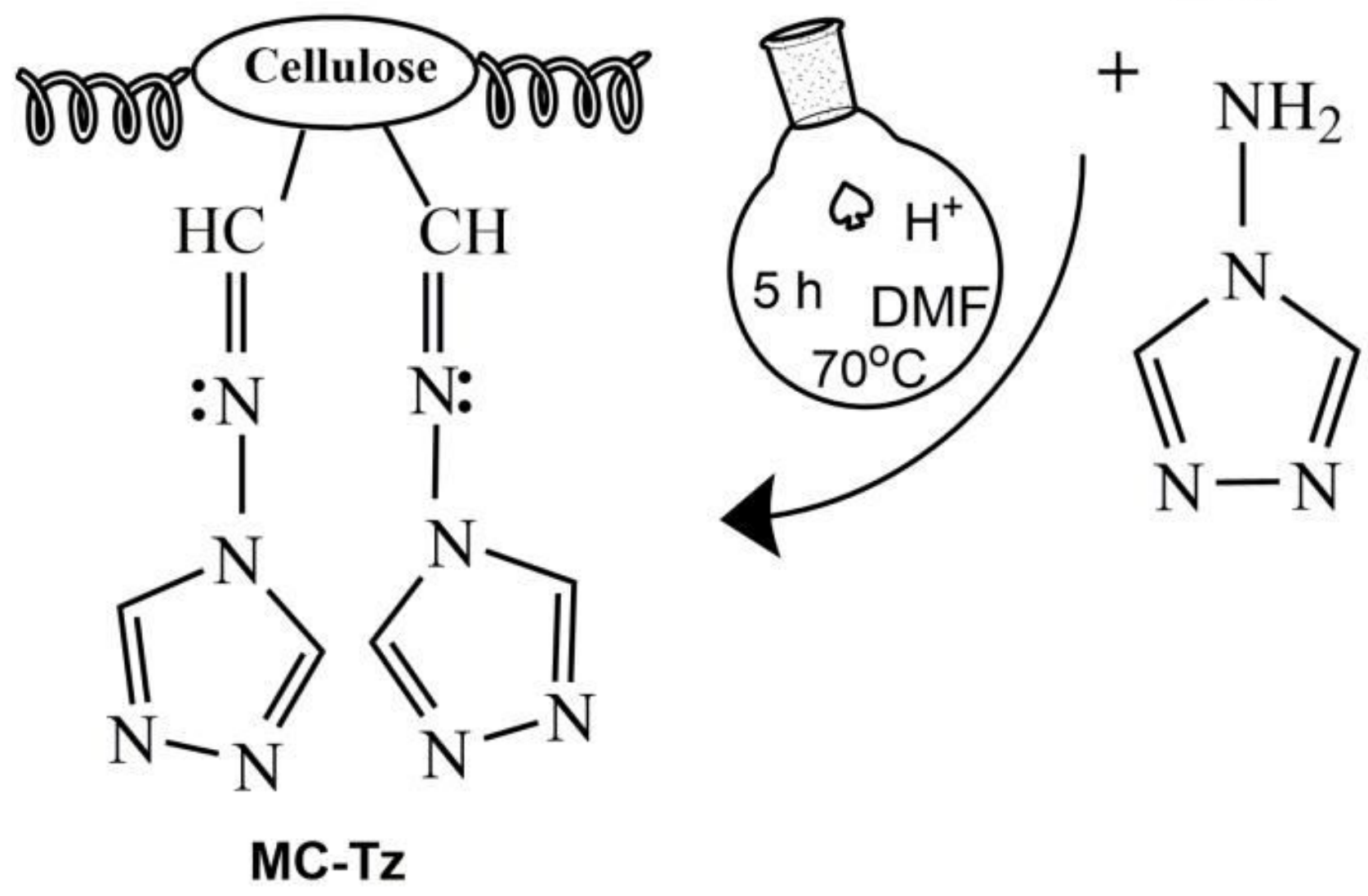

Figure 1

Scheme of MC-Tz 

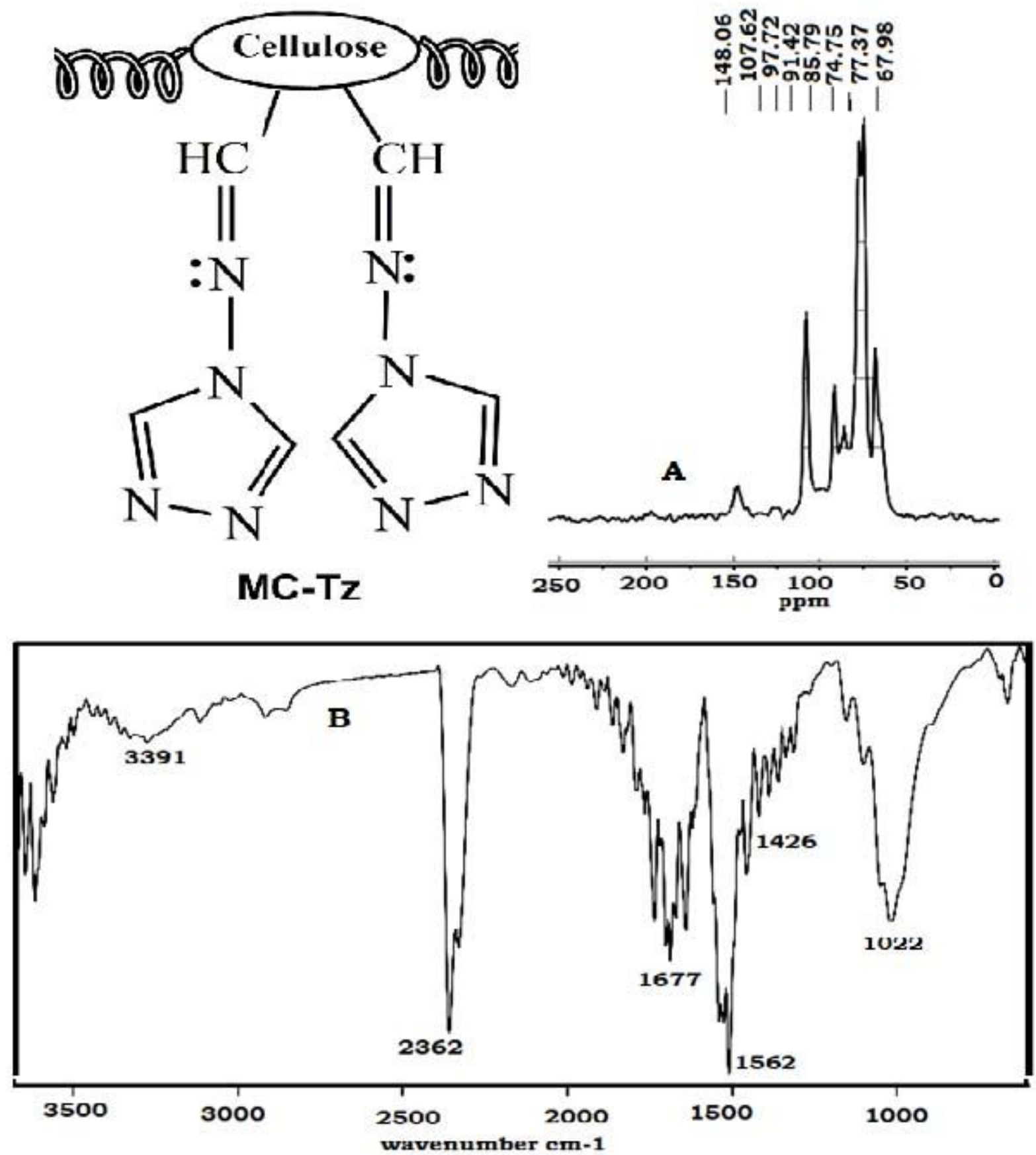

Figure 2

(A) 13C CP-MAS NMR and (B) FTIR Spectrum of MC-Tz Adsorption Studies of MC-Tz towards Lead(II), Copper(II), Nickel(II) and Cadmium(II) metal ions. 

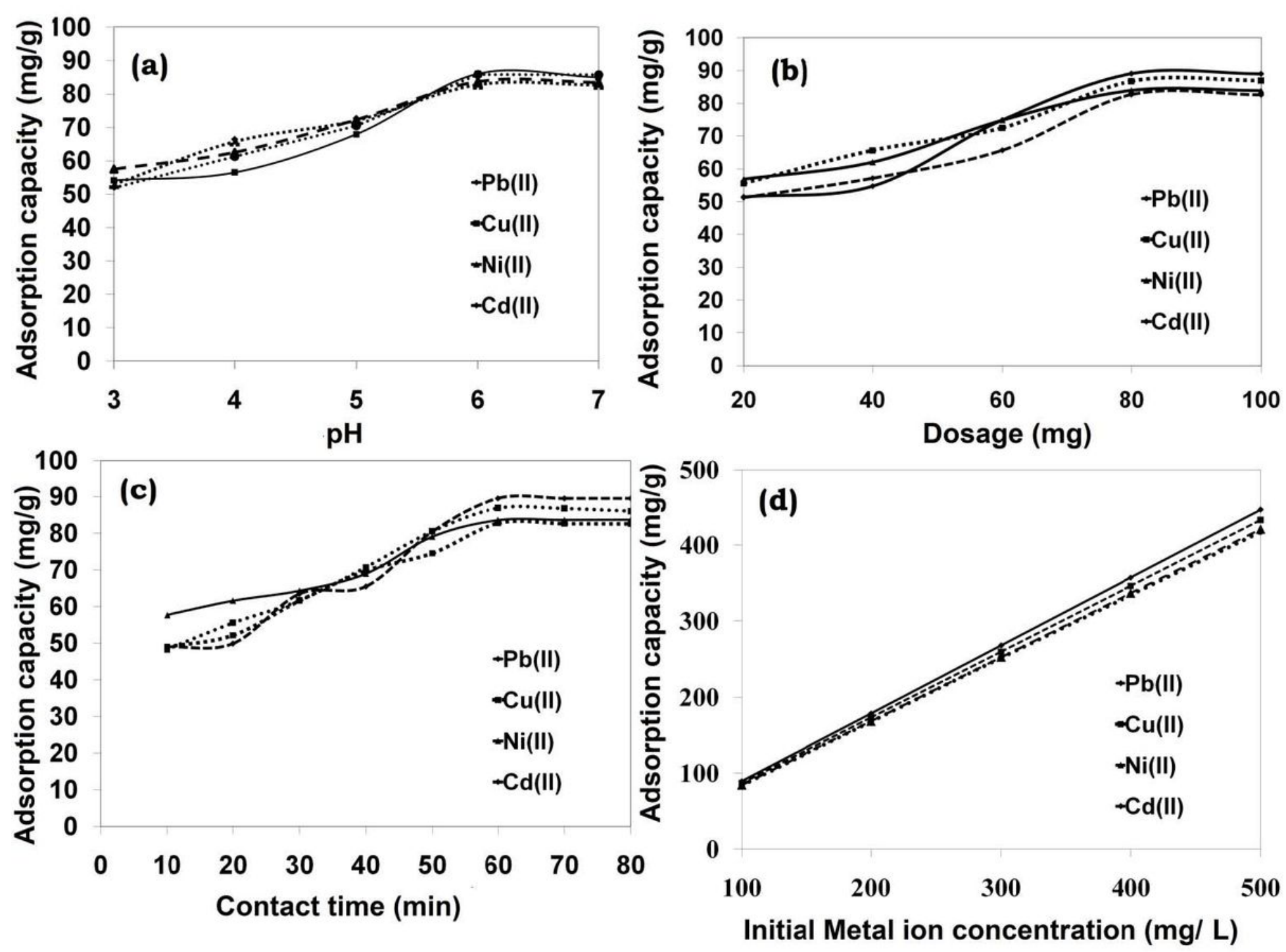

Figure 3

Effect of Adsorption parameters 

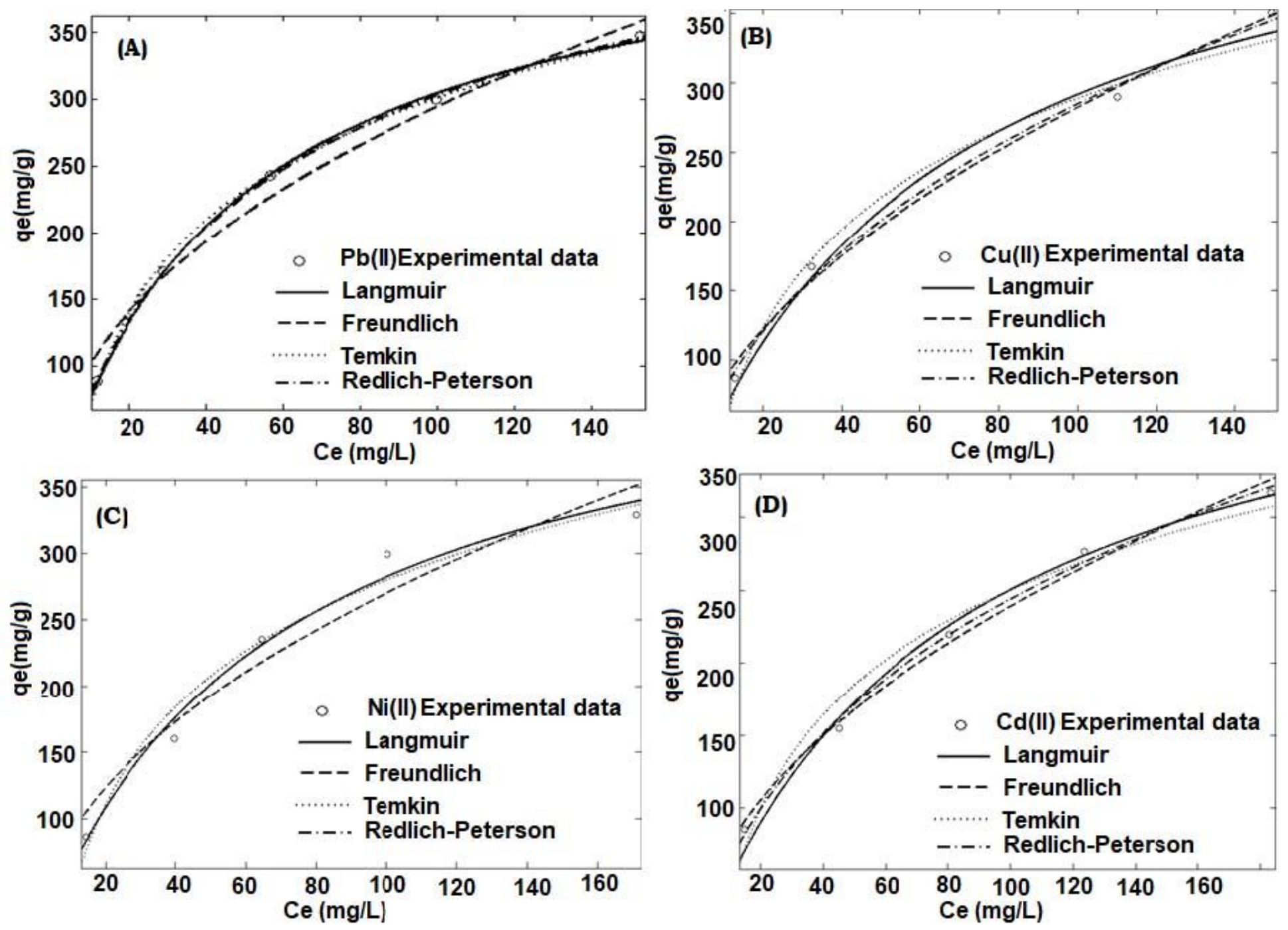

Figure 4

Non-linear adsorption isotherm for (A) Lead(II) (B) Copper(II) (C) Nickel(II) and (D)Cadmium(II) ions with MC-Tz 


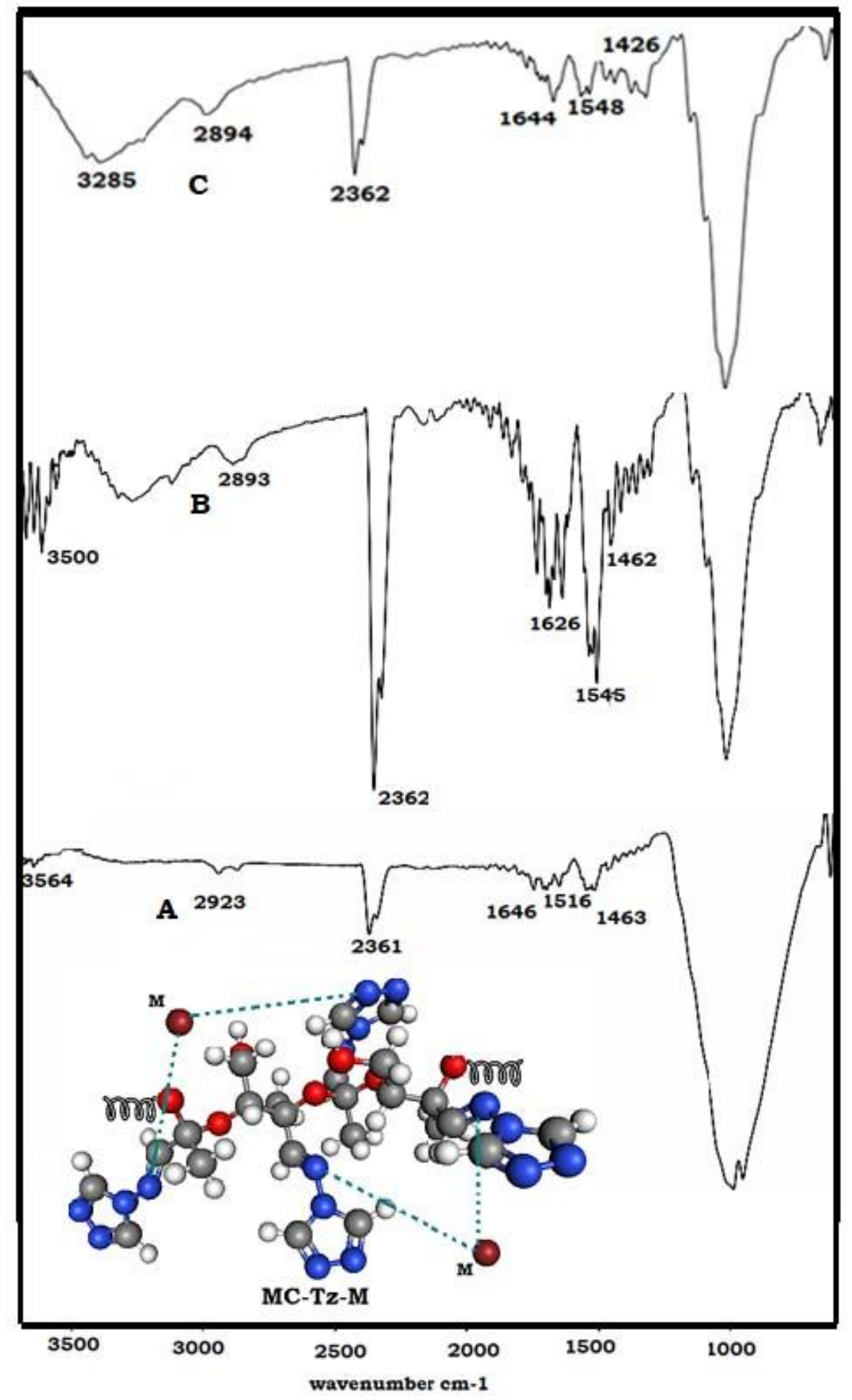

Figure 5

FTIR Spectrum of (A) MC-Tz - Pb, (B) MC-Tz-Ni and (C) CMC-Bz-Cd. 


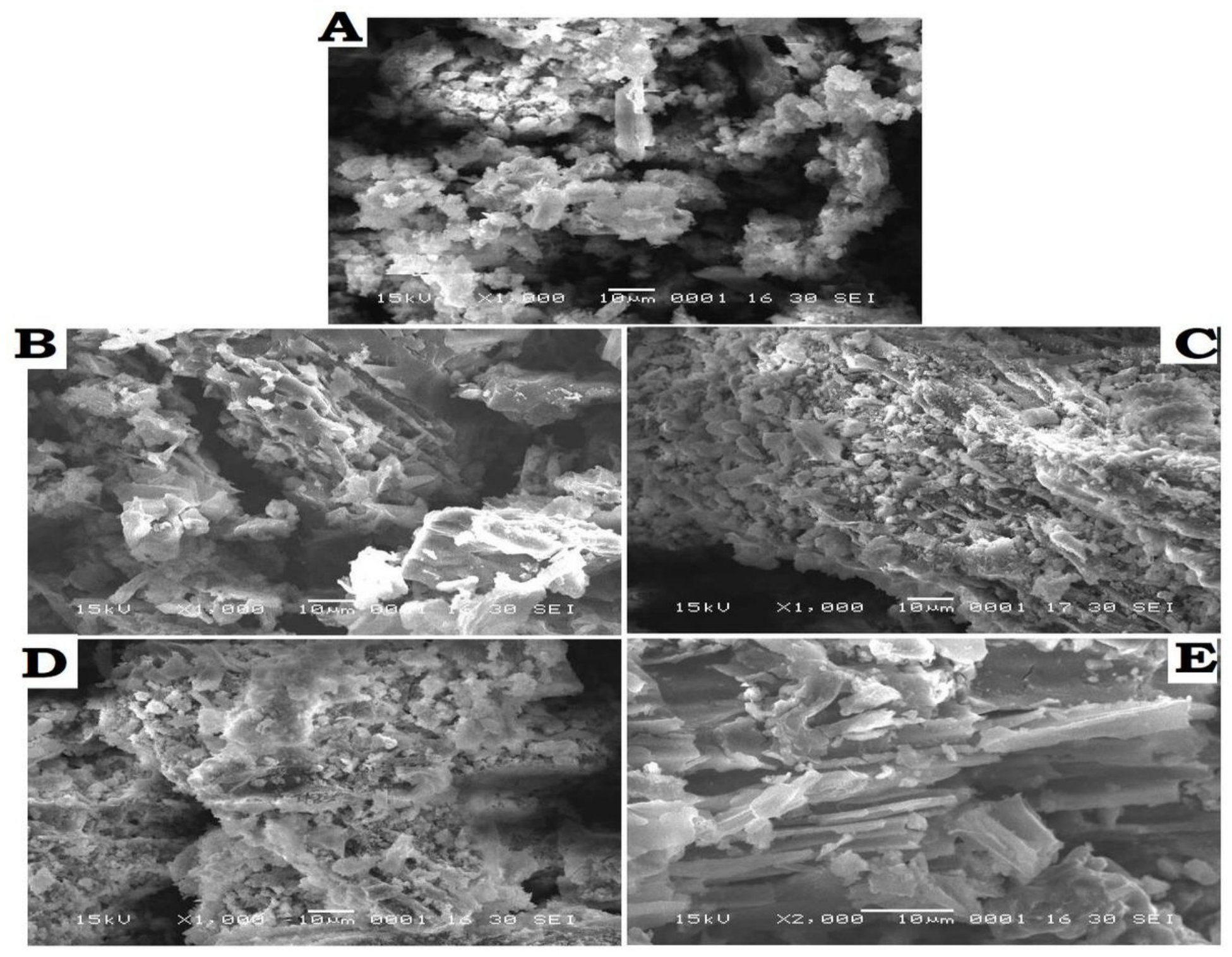

Figure 6

SEM morphology of (A) MC-Tz (B) Lead(II) (C) Copper(II) (D) Nickel(II) and (E)Cadmium(II) ions metal loaded CMC-Bz. 


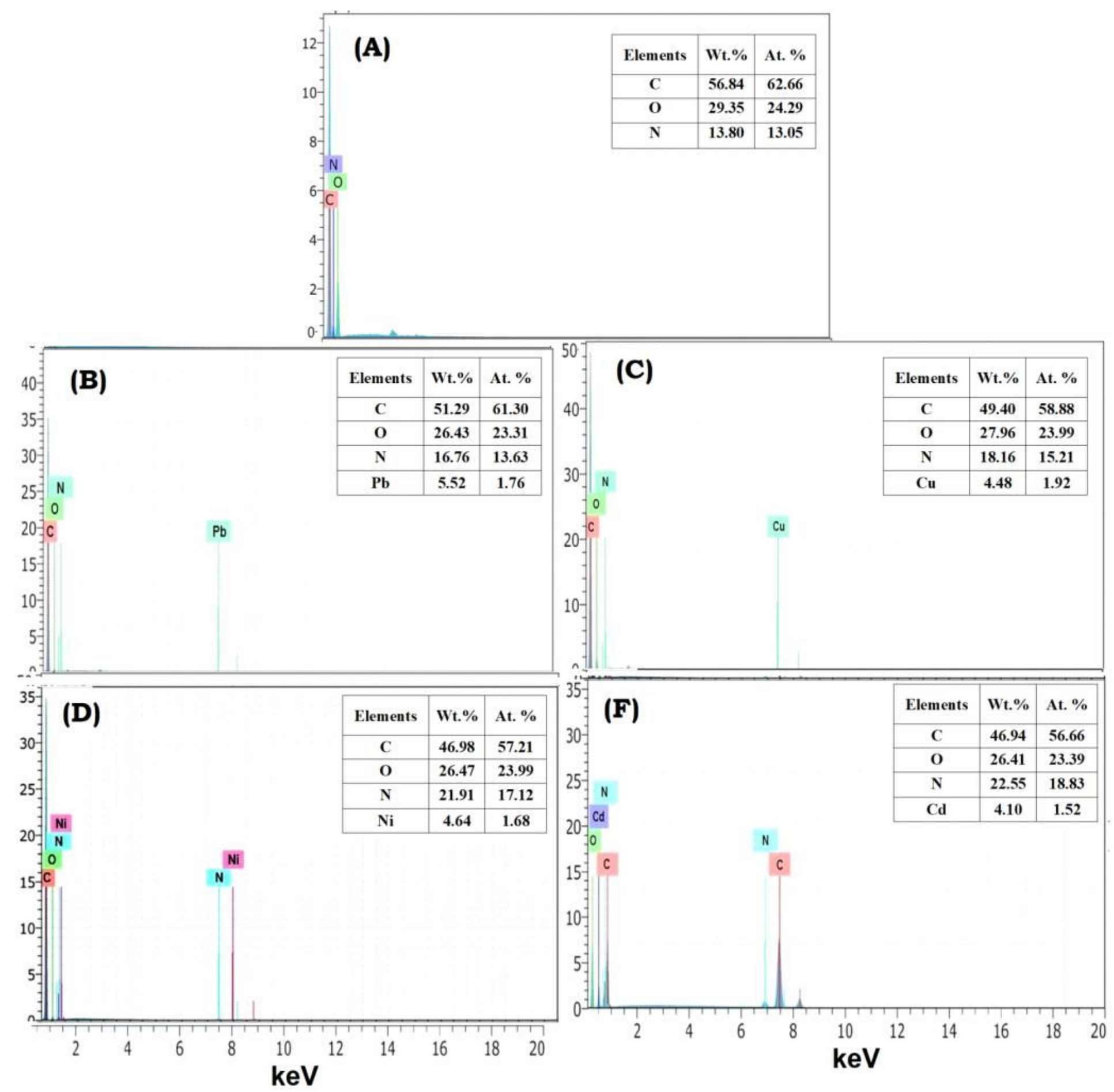

Figure 7

EDAX spectra of (A) MC-Tz (B) MC-Tz-Lead(II) (C) MC-Tz-Copper(II) (D) MC-Tz-Nickel(II) and (E) MC-TzCadmium(II) 

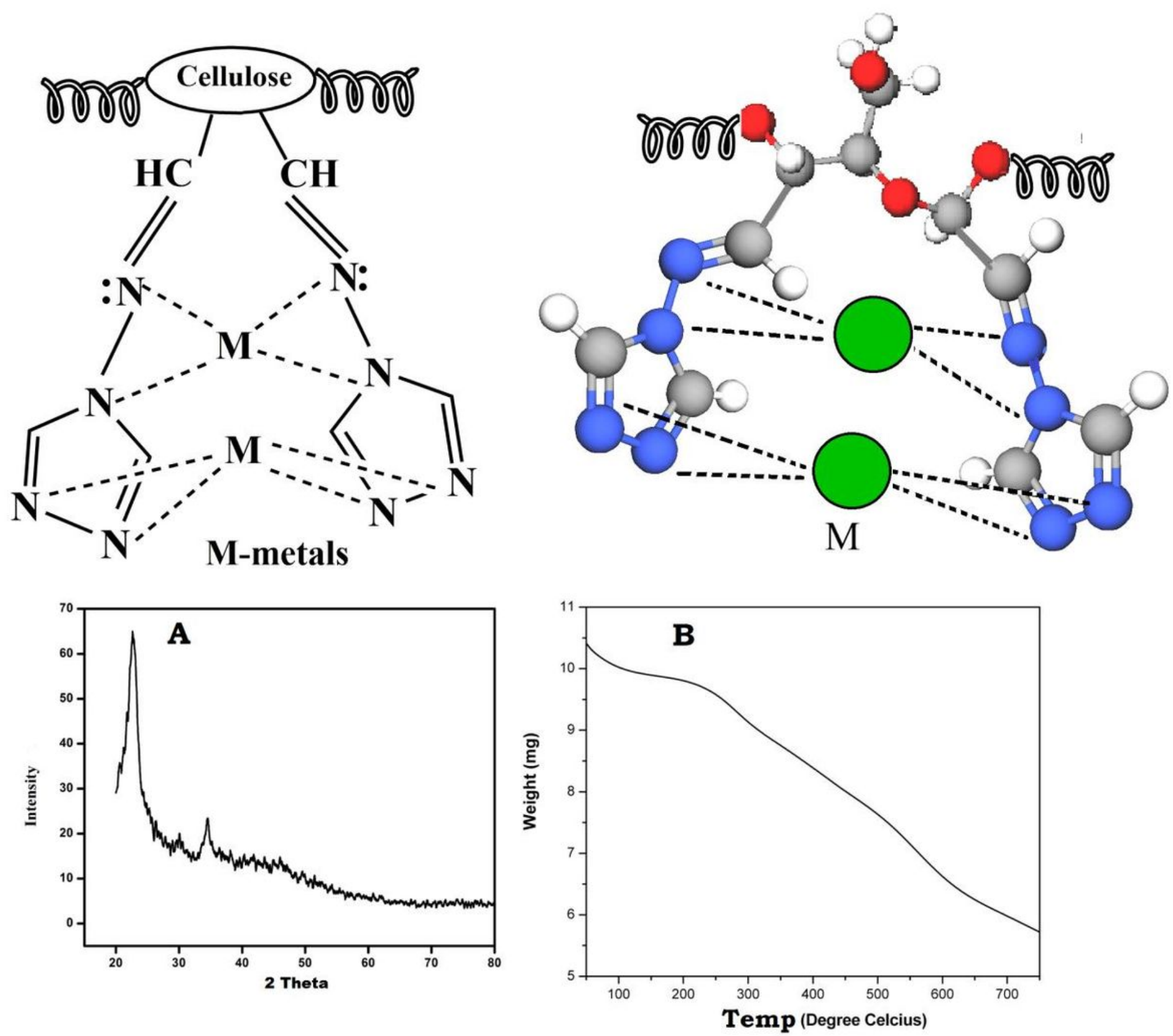

Figure 8

XRD pattern and TGA curve of MC-Tz 

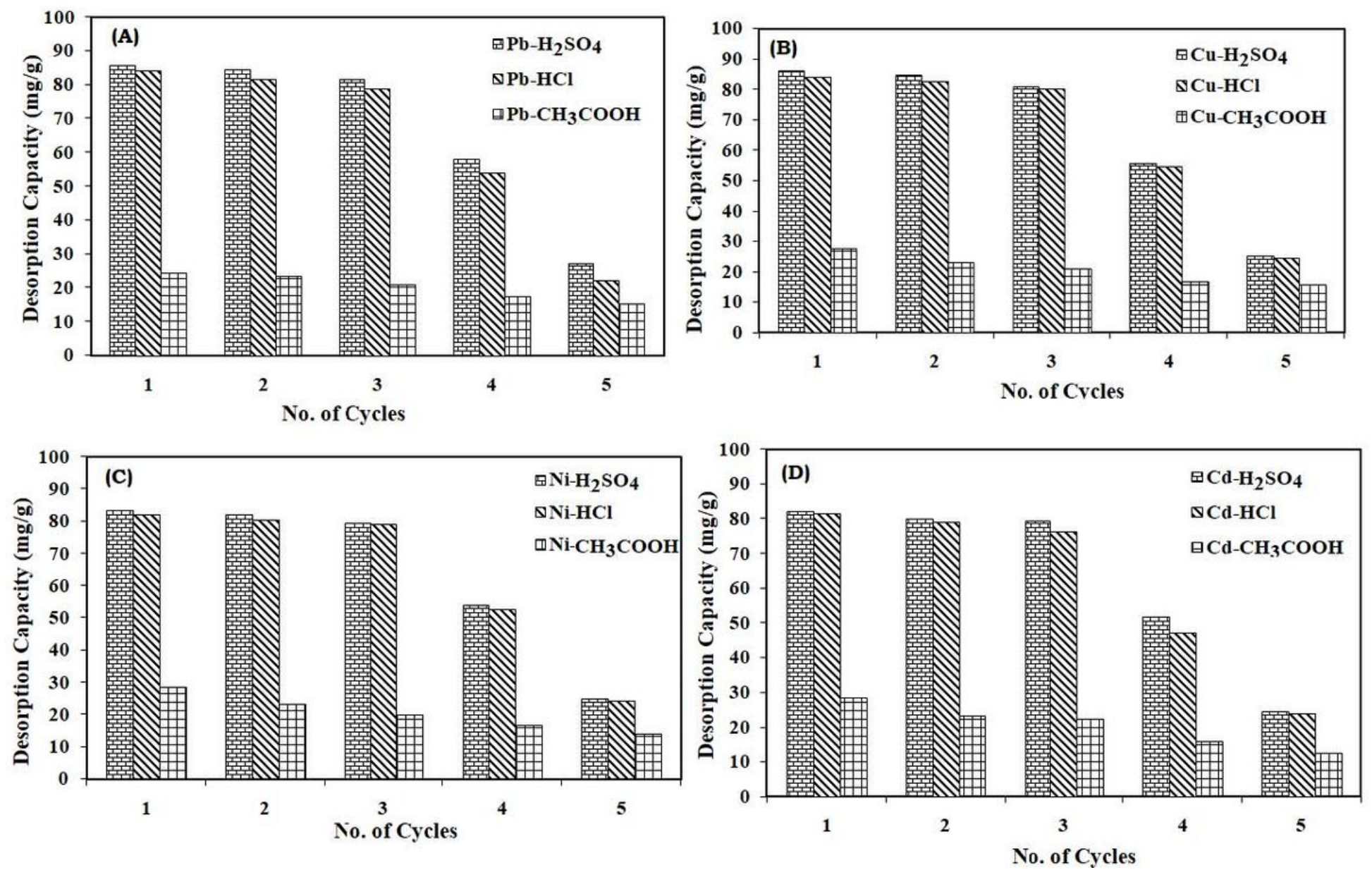

Figure 9

Recyclability of (A) Lead(II) (B) Copper(II) (C) Nickel(II) and (D)Cadmium(II) ions onto MC-Tz 